\title{
L2 Reading Comprehension: Exclusively L2 Competence or Different Competences?
}

\author{
Siping Liu \\ College of Foreign Languages and Literature, Wuhan University, China
}

\begin{abstract}
This paper is a literature review focusing on reading English as a second or foreign language (ESL/EFL). It reviews the recent empirical studies in ESL/EFL reading and by so doing it intends to lay a theoretical foundation for the development of valid tests on reading comprehension and set directions for further research on ESL/EFL reading tests. First, the paper reviews the major reading models including bottom-up, top-down, interactive and interactive-compensatory models. Next it discusses the meaning of comprehension in ESL/EFL. Finally based on the review, it raises questions for further study.
\end{abstract}

Index Terms - ESL reading, reading competence, review

\section{INTRODUCTION}

L1 reading and L2 reading each has different purposes. For L1 reading, one reads in search of specific information, in order to obtain knowledge from reading texts and for general comprehension (Grabe \& Stoller, 2002). In contrast to L1 reading, L2 readers have some different purposes associated with the reasons of learning English as a second or foreign language. They may read with effort for meaning, or learn lexical and grammatical knowledge (Pulido, 2003). On the other hand, L1 and L2 reading is also closely related. When one reads in a L2 language, one will inevitably transfer from the first language some of the competences and skills (Yamashita, 2007). Because of the differences and similarities found between L1 and L2 reading and the blurred boundary between L1 and L2 competences, to measure L2 reading is a challengeable task. Reading tests may measure more than L2 reading competences. Spolsky (1989) pointed out that a valid language test depends on a clear definition of what it means to know a language. In terms of testing $\mathrm{L} 2$ reading, it is necessary to first understand what $\mathrm{L} 2$ reading is. To validate $\mathrm{L} 2$ reading tests, the first step is to explore the nature of $\mathrm{L} 2$ reading.

This paper reviews relevant articles concerning the nature of $\mathrm{L} 2$ reading and how $\mathrm{L} 2$ reading is related to cognition. By reviewing the relevant literature I try to lay a foundation as reference for more valid reading tests, especially L2 reading. I focus on the testing of reading because of the following reasons. With the economic globalization, English has become one of most important compulsory courses in the Chinese university curriculum. Due to its importance, college students spend half of their spare time on learning English (Tan, 2007). However, compared with their effort, the Chinese students' performance on English tests (mainly composed of reading comprehension questions) is not satisfactory. Less than half of the students passed the national college English exam (ibid). In the literature researchers argued about the validity of the English examinations and contended whether such English examinations measure more than English proficiency (Cheng, 2008; Wu, 2001).

To address the problems found in the present English tests in China, it is necessary to review literature regarding the theories about English language proficiency including reading proficiency. Only we understand what L2 reading proficiency is, can we develop tests that can truly measure it.

\section{NATURE OF READING}

\section{A. Reading Process}

L2 reading research spans the last century. It was one of the issues of concern for the earliest reading research (Bernhardt, 2001). But for most of the time the research was incorporated into that of L1 reading. Judd and Buswell pointed out that "foreign language can be read in a manner directly comparable to the reading of vernacular ... the manner of reading is fundamentally the same" $(1922$, p. 91). Even today in the literature there are still studies that support the view that L1 and L2 reading is fundamentally the same. For example, Sarig (1987) studied 8 Israeli female adolescents aged between 17 and 18. She found that no matter in reading both in their first language Hebrew and the foreign language English, the students implemented the similar higher-level processing skills such as identifying main ideas and synthesizing overall information.

Despite the shared properties between L1 and L2 reading, there still exist some 'visible differences that have an impact on understanding, on perception, on social and psychological access, on processing speed and on success' (Bernhardt, 2001, p. 2). It is these differences that will be focused on during the review.

1. Bottom-up Models 
In the last 20 years or so the literature on the reading process has been dominated by cognitive psychology which attempted to apply the information processing perspective to many components of reading performance. In the early cognitive theory, information is processed on a stage-by-stage basis. Each stage transforms its input and "passes on the new recoded representation as an input to a subsequent stage". Because the sequence of processing operation moves from the incoming data to a higher-level encoding, such reading pattern is called bottom-up models (Stanovich, 1980, p. 33).

Gough (1972) states that in the more technical terms the bottom-up model works in sequence in the following procedure. First, the graphemic information goes through the visual system and is transformed from letters to sound; next, the phonemic representation of letter combination is changed into a word. The meaning units or words then pass on to the third level, i.e., the place where sentences go when they are understood and meaning is incorporated into the knowledge system. Thus, through a series of successively upward movement of encodings, input is transformed from low-level sensory information to high-level meaning (Rayner \& Pollatsek, 1989). This process is also referred to as "data-driven".
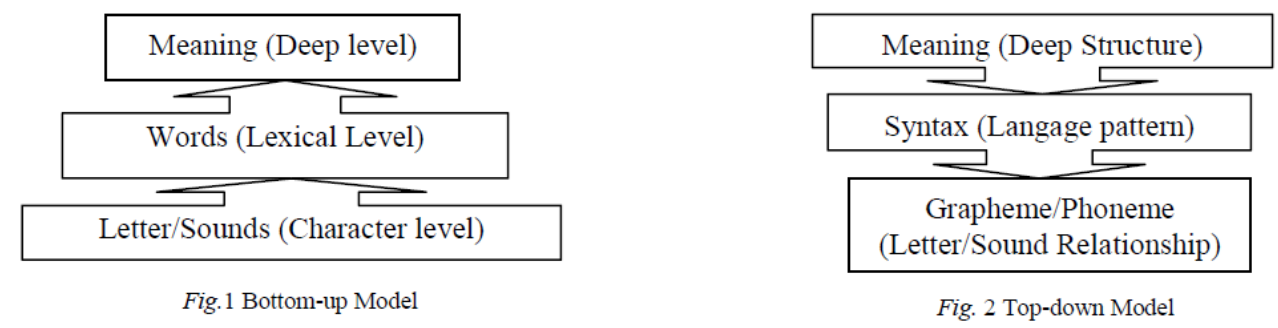

Although this data-driven model is mainly attacked for its major flaw that it doesn't explain clearly how higher-level process affects lower level, it is still useful as a criterion to distinguish a good ESL reader from a poor one. Pang (2008) reviewed recent research empirical articles about L1 and L2 reading and concluded that lower-level processing such as word recognition is an essential part of L2 reading comprehension and even for advanced ESL readers, lower-level processing is always needed for L2 reading comprehension. He also noted that for L2 reading high level reading process such as making inference is always dependent on readers' English proficiency, i.e. their lexical and syntactic knowledge of English.

In another research based on 2-year longitudinal study of ESL university freshmen who were enrolled in a university in New York, Parry (1991) found that when readers were at the stage of vocabulary development, they were unable to implement higher cognitive reading skills such as guess meaning in the context. Thus, for ESL readers with lower English proficiency, L2 reading comprehension heavily depends on the encoding of basic knowledge such as phonology, vocabulary and syntax.

2. Top-down Models

Top down theories suggest an opposite movement of bottom-up models and it argues that comprehension begins with the readers' contribution, i.e. from higher levels of processing, and readers only resort to lower levels selectively. A typical top-down theory is Goodman's oft-quoted view of reading as a "psycholinguistic guessing game" (1967, p. 126). From the perspective of top-down theories, reading is seen as a constant process of guessing. Readers process reading not by reading every word. Instead, they sample the text, predict what may come next, and then sample the text again to confirm their predictions (Grellet, 1981). The amount of reading that readers process depends on how well they can guess the meaning. Such theories also suggest that readers can use meaning and grammatical cues to identify unrecognised words and reading for meaning is the primary objective of reading rather than mastery of letters, letter/sound relationships, and words (Smith, 1994; Gove, 1983). For the reader, the most important aspect about reading is the amount and kind of information gained through reading.

In this model it is evident that the flow of information moves from the higher level and as a result the recognition of word meaning depends on textual meaning first. Thus the higher level processes embodied in past experience (semantics) and the reader's knowledge of the language pattern (syntax) interacts with and direct the flow of information (Stanovich, 1980, p. 35).

Like bottom-up model, top-down model is also challenged for its limitations, though the theory claims that it is a universal process (Goodman, 1998). Eskey points out that "they tend to emphasize such higher-level skills as the prediction of meaning of context clues or certain kinds of background knowledge at the expense of lexical and grammatical forms" (1998, p. 94). Above all, the perceptual and decoding dimensions still have a major role to play in fluent reading. In Eskey's words, good reading is a more language-structured affair than the guessing-game metaphor seems to imply (ibid). Urquhart and Weir also critically comments:

"It is virtually impossible to see how a reader can begin by dealing with the text as a whole, then proceed to smaller units of the text, then down to individual sentences, ending with single letters. In fact, the term 'top-down' is deceptive, appearing to offer a neat converse to 'bottom-up', a converse which in reality does not exist” (1998, p. 42).

For ESL or EFL reading, top-down model seems to be more applicable to those who are more proficient in the target language. Because they encounter little or even no phonemic, semantic or syntactic problems in the text, they can spare 
their attentional resources more cognitively than perceptually for the rendezvous of meaning from the text and the background knowledge and prior knowledge from their long-term memory (Widdowson, 1983). Pulido (2007) suggested that readers' prior knowledge is activated by the quality of the text they are reading. This is especially true for ESL readers. If the content and difficulty of the text matches their prior knowledge, more proficient ESL readers may read equally well as L1 readers. Pulido investigated ninety-nine adult Spanish learners, who were taking elementary, intermediate and advanced levels of Spanish course respectively at university level. Pulido selected four script-based narrative passages and two of them were familiar to the participants and two were unfamiliar to measure their lexical gain and retention. He found that weaker readers had less lexical gain than stronger readers when they experienced more constraints in the text such as unfamiliar words. Pulido explained the constraints increased the participants' load on processing lexical items and therefore they allocated less attention to using strategies for constructing meaning. This demonstrates that ESL readers are not consistent in implementing top-down reading model. When the difficulty of a text is raised above the level of their proficiency or beyond prior knowledge, they have to allocate more attention to process lexical or syntactic items, a typical bottom-up model.

Lee (2009) did a similar study on sixty Korean English L2 readers, who were either undergraduates or graduates studying in American and Korean universities. The author addressed the question of how topic congruence and topic interest affect the quality of L2 readers' reading comprehension. Based on their score on standard tests, the participants were divided into upper-intermediate to advanced-level English users. Lee chose two argumentative articles addressing the same issue from either positive or negative perspective and he asked the participants to write down what they read. The first question, topic congruence, is concerned with the question whether or not the content corresponds with the participants' prior beliefs and the second question, topic interest, is concerned with whether the content appeals to them. He used "repeated measures multivariate analysis of variance (MANOVA) with topic congruence as a within-subjects factor and topic interest as a between-subjects factor" (2009, p. 168). Data analysis revealed that high topic interest group outperformed the low topic interest group and the author suggested that topic interest is an important factor that can help ESL readers retain better the textual information. The author also found that when reading a text congruent with the readers' prior belief, they might overlook the detailed information. On the other hand, the text with incongruent topic drew the readers' more attention to process information with low content value.

These two studies indicate that whether to use top-down model or not, the familiarity of a text is a decisive factor for ESL readers. This is especially applied to less proficient ESL readers, who seem to be deprived of their attention for the interpretation of linguistic meanings or they have to attend more to bottom-up process than native English readers (Eskey, 1998) because ESL readers are mostly not linguistically qualified for guessing.

Wildman and King (1980) argued that information in most of reading texts is in fact neither sufficiently redundant nor adequately predictive to make hypotheses, i.e., "top-down" model to operate effectively. Because various factors involved in L2 reading, L2 readers are found to read in a bimodal pattern or interactive pattern, i.e., from both bottomup and top-down models.

3. Interactive Model

An interactive reading model, a model based on psycholinguistics, attempts to combine the valid insights of bottomup and top-down models and recognizes the interaction of bottom-up and top-down processes simultaneously throughout the reading process. It is parallel rather than serial (Grabe, 1991) and it tries to "avoid the criticisms levelled against each of the model" (McCormick, 1988, p. 29) by providing "a more accurate conceptualisation of reading performance" (Carrell, 1998).

The blend of bottom-up and top-down models is what Rumelhart (1984) proposes, who thinks that reading is at once a perceptual and a cognitive process, which bridges and blurs these two traditional distinctions.

In his opinion, readers vary their focus along a continuum from primarily text-based processing to primarily readerbased processing and bottom-up and top-down processing interacts in a complex mechanism of triggering and anticipation (ibid). Based on this theory, the processing of text is a flexible interaction of all the different information sources that are available to the reader; and information contained in higher stages of processing can influence the analysis that occurs at lower stages of analysis, as well as the other way around. Readers can process a reading text by using one or more of the possible information sources as their primary clues to process meaning: semantic context, syntactic environment, or surrounding letters (ibid). But the initial trigger of high-order process seems to be the incoming textual data (bottom-up) which activates appropriate higher level schemata (top-down) against which the reader tries to give the text a coherent interpretation.

Leeser (2007)'s study on the interplay between topic familiarity and working memory in ESL reading comprehension offers further explanation on how ESL readers shift between top-down and bottom-up models. The author investigated 94 undergraduates learning Spanish at beginning level. One group of the participants read two reading passages with familiar topic and another group read two passages with unfamiliar topic. Afterwards, they completed a written recall protocol in their first language. Based on post hoc analysis, Leeser found that if the participants were familiar with the topic, they benefited from higher working memory but in doing unfamiliar task, the author also noted the participants' high working memory but it is used to compensate for unfamiliarity on the text. The author explained that readers integrate textual information with their prior knowledge but when the text is unfamiliar to readers, readers may not have relevant prior knowledge to draw and as a result, higher levels of WM might not facilitate comprehension. Leeser's 
findings lend further support to Rumelhart (1984)'s theory that bottom-up and top-down processing interacts in a complex mechanism and information contained in higher stages of processing can influence the analysis that occurs at lower stages of analysis, as well as the other way around. Thus, high WM may either process bottom-up or top-down information depending on the familiarity of the text.

Leeser's findings seem to echo Dechant's explanation that the reader constructs meaning by the selective use of information from all sources of meaning (graphemic, phonemic, morphemic, syntax, semantics) without adherence to any one set order. The reader simultaneously uses all levels of processing even though one source of meaning can be primary at a given time" (1991, p. 27). Goodman also stated that readers provide input, too, and the reader, interacting with the text, is selective in using just as little of the cues from text as necessary to construct meaning". (1981, p. 477)

In short, "reading is regarded not as a reaction to a text but as interaction between the writer and the reader mediated through the text" (Widdowson, 1982, p. 174).

However, just I mentioned earlier, ESL or EFL readers are only qualified to read interactively under the condition that they are proficient enough in the target language. A wealth of empirical work demonstrates that readers can interpret and evaluate an author's message only to the extent that they possess and call forth the vocabulary, syntactic, rhetorical, topical, analytic, and social knowledge that the author has presumed, as well as a number of theories and models of the psychological structures and processes involved in bringing such knowledge to bear (Anderson \& Pearson 1984).

In view of this linguistic and cultural threshold, interactive-compensatory appears to be more palatable to the research of ESL and EFL reading.

4. Interactive-Compensatory Model

The interactive-compensatory model provides truthful insights into the nature of reading, especially for EFL reading (Stanovich 1980). It is interactive because readers process the meaning of a text by decoding the linguistic information (bottom-up processing) and by relating this information to what they already know about the world (top-down processing). The background knowledge is accumulated through one's experience of the world and is stored in abstract knowledge structures known as "schemata" (Adams and Collins, 1979).

And it is compensatory in the sense that "a deficit in any knowledge source results in a heavier reliance on other knowledge sources" (Stanovich, 1980, p. 63) or readers compensate the deficiency of level by drawing either other higher or lower levels (Nunan, 1995). In other words, if a reader's linguistic knowledge is weak at any one point, s/he will compensate by drawing on background knowledge, and vice versa. The model assumes that top-down and bottomup processes are equally important in processing a text. To my understanding, this model also provides the result from empirical studies that language competence is componential (Volmer, 1983).

Yau (2009) made a comparative study on Chinese students' use of strategies in reading both Chinese and English. She selected a total of 144 Grade 11 students for her study. She used correlational analysis and $t$-test to analyze quantitative data of English reading comprehension test and two reading strategies questionnaires and she also used the constant comparative method to analyze qualitative data of semi-structured interviews and think-aloud protocols. She found that the participants used quite different sub-categories of reading strategies, though the overall uses of L1 and L2 strategies were not significantly different. For example, she noted that the participants more frequently used metacognitive and cognitive strategies when they read in their first language and they used more support strategies when they read in English. Another interesting finding Yau revealed is that when the participants read the texts written in classic Chinese and in English they used similar strategies, though they used different strategies when they read texts written in classic Chinese and modern Chinese. Yau explained that when reading in classic Chinese (different from modern Chinese) and English, the students resorted to mental translation but such translation was not necessary when they read modern Chinese. This conclusion corresponds with Stanovich (1980)'s interactive-compensatory model in that the readers compensate for "a deficit in any knowledge source results in a heavier reliance on other knowledge sources".

In conclusion, I have reviewed four kinds of reading models supported with recent empirical studies. It can be seen that $\mathrm{L} 2$ readers read without exclusively resorting to one single model. Under certain conditions, readers may read from top-down or bottom-up (Rumelhart, 1984). L2 reading is multidimensional in that many factors are involved in the processing of textual information. My brief review blurs the boundaries among the different models and it may serve as a definition of the nature of $\mathrm{L} 2$ reading for $\mathrm{L} 2$ reading tests.

\section{B. Comprehension}

The core of reading comprehension is the search and struggle for meaning, hidden from the outside observers (Block, 1980). Generally speaking, comprehension is the understanding of what an author conveys in his/her text. This statement, however, is certainly subject to attack since there are many variables that will decide how we understand a text. From readers' perspective, the factors that influence comprehension include affect, background metalinguistic intuition, goal, and language aptitude (Swaffer, 1988). Readers naturally think that when they read they are attempting to reach for $100 \%$ or ideal comprehension. But the concept of ideal comprehension itself is confusing. Is it an exact photocopy of the writer's proposition to the readers' mind or what William (1986) states "an accurate image" of the writer's intention. If the answer is yes, some other questions arise: what are the standards of the complete reflection of 
the writer's intention? and who are qualified to be the judges? Certainly test developers are not well qualified unless their mind is a cloning of the author's.

Urquhart suggests that comprehension is the different product of the reading process and the "the standards which comprehension depends on are more or less under the conscious command of the reader" (1987: 387). In the similar vein, Goodman sees reading comprehension as readers' restructuring of author's message (1967). Readers reconstruct what they read because of the role their schemata play during reading. Bruning et al (2004) explained that readers' understanding was created within the knowledge framework that was activated prior to reading and comprehension is readers' interaction between the reading passages and their schemata (Nassaji, 2007). Florencio (2004) investigated the reading comprehension of 51 Brazilian university students learning English and 66 American university students. The author asked the participants to read two passages, one with a familiar content and the other with unfamiliar content. After reading, he then asked them to complete multiple choice and cloze questions based on the passages. Based on the analysis of Variance (ANOVAS) with repeated measures that "determine the effects of the independent variables of passage content (familiar and unfamiliar) and groups (American and Brazilian) on the dependent variables, speed, comprehension question and cloze task" (p. 62), the author found that the participants scored much higher and read faster when they read the text of familiar content. The author concluded that reading comprehension goes beyond readers' linguistic competence and their background knowledge is a decisive component in their reading comprehension. Finally, the author suggested that L2 teachers should attribute students' reading comprehension problems not only to linguistic difficulties but also to cultural elements. This indicates that thorough understanding of a text depends on readers' contribution from their schema.

But unfortunately, in taking a test of reading, the readers' contribution is weakened by test constructors and readers, or test takers to be more exact, are disadvantaged in the sense that they cannot argue with test constructors for a different interpretation. But this under-privilege doesn't mean that comprehension in tests is equivalent to comprehension questions. How then can readers and test constructors find an interface on which both have some shared patterns? Figure 3 shows how the real reading comprehension works (Block, 1980).

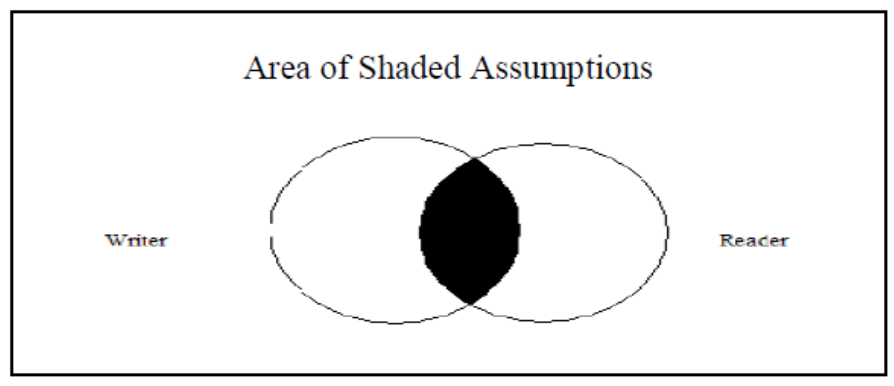

Fig. 3 The Communication between the writer and the reader

The shaded area where the two circles overlap represents what the reader and writer have in common. It is like a lunar eclipse but certainly it is not a total one. 100\% comprehension, like a total eclipse, seldom happens. This is because the intangible things like attitudes, beliefs and values are different among readers (ibid), writers and test constructors and how readers comprehend will depend on their individual perspectives and background "because meaning and structure of a text are not inherent in the print but are invited by the author and imputed to the text by the reader" (Schallert, 1996, p. 272). Therefore, what we hope for the best is a larger eclipse or more shaded area. To guarantee this, writers and readers should be closely similar in background knowledge, training and attitude as well as sufficient decoding abilities (Paran, 1996). What's more, a longer time is also needed for deeper understanding. To keep a balance between the depth of understanding and the length of time, what Fry (1963) recommends may be a compromise: $70 \%$ to $80 \%$ comprehension at the right speed. A better comprehension might be possible but can only be achieved at a snail's pace.

But Fry's recommendable comprehension of $70 \%-80 \%$ still blurs the question of understanding, as there exist different levels of understanding. Gray (1960) distinguishes understanding in three levels: reading 'the line', reading 'between the line' and reading 'beyond the line', which refer respectively to literal meaning, inferred meaning and readers' critical evaluation of the text. Because the second and third levels are subjective in nature, they will inevitably bring about a mismatch of some kind between the reader and the writer and the readers' objective agreement is only limited to explicit statement, or the first level (Swaffer, 1988).

At the conclusion of the review we should still be reminded that reading comprehension is relative and readers are said "to have understood the text when they are able to find a configuration of hypotheses which offers a coherent account for the various aspects of the text" (Rumelhart, 1984).

\section{FURTHER RESEARCH AND IMPLICATION}

The general review indicates that reading is a complex process that involves different elements such as L2 readers' English proficiency, prior knowledge, content familiarity and even their L1 reading competency. To justify the validity 
of a reading test, test developers need to take the complex nature of reading into consideration. Based on the review, I argue that L2 reading tests should be studied in situated context (Anderson et al, 1996) and in multiple methods, i.e, situated and multi reading tests. By situated context, I mean test developers first need to consider various elements such as the purposes, test takers and the context of tests. If the reading content of a test corresponds to the readers' prior knowledge, the test may fail to measure students' lexical and syntactic competencies because readers can compensate their lack of linguistic competences with their prior knowledge. Multiple methods refer to the variation of testing methods. If we intend to measure English proficiency rather than anything else such as L1 reading competency or background knowledge, we should implement a variety of methods and select reading passages with different topics. An integrated picture will better reflect L2 readers' reading proficiency.

My review also sets directions for further research on the tests of reading, especially the validation study of some of the important and high stake tests administered in China such as college entrance exam and college exit exam. I suggest that further empirical research cover the following aspects of testing reading comprehension:

1. Reading content (topic familiarity and difficulty of texts)

2. Purpose of testing reading (Students' reading ability or lexical and syntactic abilities)

3. Students (background knowledge, years of learning English and purpose of taking tests)

4. Importance (high stake, standardized tests)

5. Scale (nationwide or tests for specific people)

6. Format (text presentation, picture aids and methods of questions)

7. Time (time constraints)

\section{ACKNOWLEDGEMENT}

The paper is part of the research for the "2014 Social Science Research Grant of Hubei Province", China.

\section{REFERENCES}

[1] Alderson, R. C., \& P. D. Pearson. (1984). A schema-theoretic view of basic processes in reading. In P. D. Pearson, (ed.), Handbook of Reading Research. New York: Longman.

[2] Anderson, J. R., Simon, H. A., \& Reder, L. M. (1996). Situated learning and education. Educational Researcher, $25,5-11$.

[3] Block, N. J. (1980). Readings in the philosophy of psychology. Cambridge MA: Harvard University Press.

[4] Bernhardt E.B. (2001). Progress and procrastination in second-language reading research. Retrieved March 16, 2010, from the website: https://www.stanford.edu/dept/lc/language/about/conferencepapers/AAALBernhardt01.pdf.

[5] Bruning, R. H., Schraw, G. J., Norby, M. M. and Ronning, R. R. (2004). Cognitive psychology and instruction. Upper Saddle River: NJ: Publisher Prentice Hall.

[6] Carrell, P. L. (1998). Some causes of text-boundedness and schema interference in ESL reading. In Carrell, P.L. J. Devine \& D. Eskey. Interactive approaches to second language. Cambridge: Cambridge University Press.

[7] Cheng, L. (2008). The key to success: English language testing in China. Language Testing, 25(1), 15-37.

[8] Dechant, E. (1991). Understanding and teaching reading: An interactive model. Hillsdale, NJ: Lawrence Erlbaum.

[9] Eskey, D. E. (1998). Holding in the bottom: An interactive approach to the language problems of second language readers. In Carrell, P.L., Devine, J. and Eskey, D.E. (eds.). Interactive approach to second language reading. Cambridge : Cambridge University Press.

[10] Florencio, D. C. (2004). The role of prior background knowledge in the reading comprehension of EFL Brazilian college students and American college students. Unpublished doctoral thesis, the Pennsylvania State University, Pennsylvania.

[11] Fry, E.B. (1963). Teaching faster reading: A manual. Cambridge: Cambridge University Press.

[12] Goodman, K. S. (1967). Reading: A psycholinguistic guessing game. Journal of the Reading Specialist, 6(1), 126-135.

[13] Gough, P.B. (1972). One second of reading. In Kavenaugh J.F. \& I.G. Mattingly (eds.), Language by Ear and by Eye. MA: MIT Press.

[14] Gove, M. K. (1983). Clarifying teacher's beliefs about reading. The Reading Teacher, 37(3), 261-268.

[15] Grabe, W. (1991). Current developments in second-language reading research. TESOL Quarterly, 25(3), 375-406.

[16] Grabe, W., \& Stoller, F. L. (2002). Teaching and researching reading. London: Longman.

[17] Gray, W.S. (1960). The major aspects of reading. In H. Robinson (ed.) Sequential developement of reading abilities. Chicago: Chicago University Press.

[18] Grellet, F. (1981). Developing reading skills. Cambridge: Cambridge University Press.

[19] Judd, C. T., and Buswell, G. T. (1922). Silent reading: A study of the various types. Chicago: University of Chicago Press.

[20] Lee, S. (2009). Topic congruence and topic interest: How do they affect second language reading comprehension? Reading in a Foreign Language, 21(2), 159-178.

[21] Leeser, M. (2007). Learner-based factors in L2 reading comprehension and processing grammatical form: Topic familiarity and working memory. Language Learning 57(2), 229-270.

[22] McCormick, T. W. (1988). Theories of reading in dialogue: An interdisciplinary study. New York: University Press of America.

[23] Nassaji, H. (2007). Schema theory and knowledge-based processes in second language reading comprehension: A need for alternative perspectives. Language Learning, 57(1), 79-113.

[24] Nunan, D. (1995). Content familiarity and the perception of textual relationships in second language reading. RELC Journal, 16, 42-51.

[25] Pang, J. (2008). Research on good and poor reader characteristics: Implications for L2 reading research in China. Reading in a Foreign Language, 20(1), 1-18. 
[26] Paran, A. (1996). Read in EFL: Fact and fiction. ELT Journal, 50(1), 25-34.

[27] Parry, K. (1991). Building a vocabulary through academic reading. TESOL Quarterly, 25, 629-653.

[28] Pulido, D. C. (2003). Modeling the role of second language proficiency and topic familiarity in second language incidental vocabulary acquisition through reading. Language Learning, 53, 233-284.

[29] Rayner, K. \& Pollatsek, A. (1989). The psychology of reading. Upper Saddle River: NJ: Prentice Hall.

[30] Rumelhart, D. E. (1984). Understanding understaning. In: Flood, J. (ed.) Understanding Reading Comprehension. Delaware: IRA

[31] Sarig, G. (1987). High-level reading in the first and in the foreign language: some comparative process data. In J. Devine, P. L. Carrell \& D. E. Eskey (Eds.), Research in reading in English as a second language (pp. 107-123). Washington: Teachers of English to Speakers of Other Languages.

[32] Schallert, D. L. (1996). How coherence is socially constructed in oral and written classroom discussions of reading assignments. Yearbook of the National Reading Conference, 45, 471-483.

[33] Smith, F. (1994). Understanding reading. Hillsdale, NJ: Lawrence Erlbaum Associates

[34] Spolsky, B. (1989). Conditions for second language learning. Oxford: Oxford University Press.

[35] Stanovich, K. E. (1980). Toward an interactive- compensatory model of individual differences in the development of reading fluency. Reading Research Quarterly, 16, 32-71.

[36] Swaffer, J.K. (1988). Readers, texts, and second languages: The interactive processes. The Modern Language Journal, 72(2), 123-149.

[37] Tan, Z. (2007). Questioning in Chinese university EL classrooms: What lies beyond it? RELC Journal, 38(1), 87-103.

[38] Urquhart, A. H. \& Weir, C. (1998). Reading in a second language: Process, product and practice. Harlow: Longman

[39] Volmer, H.J. (1983). The Structure of foreign language competence. In Hughes, A. and Porter, D. (eds.), Current developments in language testing. London: Academic Press.

[40] Widdowson, H.G. (1983). Learning purpose and language use. Cambridge: Cambridge University Press.

[41] Wildman, D. M. and King, M. (1980). Semantic syntactic, and spatial anticipation in reading. Reading Research Quarterly, 14(2), 128-164.

[42] Wu, Y. (2001). English language teaching in China: trends and challenges. TESOL Quarterly, 35(1), 191-194.

[43] Yamashita, J. (2007). The relationship of reading attitudes between Ll and L2: An investigation of adult EFL learners in Japan. Language Testing, 41(1), 81-105.

[44] Yau, J. C. (2009). Reading characteristics of Chinese-English adolescents: Knowledge and application of strategic reading. Metacognition Learning, 4, 217-235.

Siping Liu was born in Wuhan, China. He received MA degree in applied linguistics from the University of Sheffield, United Kingdom in 2002 and Ph.D. degree in teacher education from University of Nevada Las Vegas, United States in 2012.

$\mathrm{He}$ is currently an associate professor in the College of Foreign Languages and Literature, Wuhan University, Wuhan, China. His research interests include educational linguistics, applied linguistics and American education.

Dr. Liu is a member of the American Educational Research Association, the Comparative and International Education Society and TESOL International Association. 